\title{
Characteristics of the atmospheric ducts over the South China Sea pre- and post-monsoon onset in 1998
}

\author{
Cheng Yin-he \\ College of Ocean and Meteorology \\ Guangdong Ocean University, GOU \\ Zhanjiang, China \\ e-mail: yinhe_9951@163.com
}

\begin{abstract}
The atmospheric duct has great scientific significance and great value for propagations of radio waves and functions of surveillance equipments. Based on the Global Positioning System (GPS) sounding data during the South China Sea (SCS) Monsoon Experiment (SCSMEX) in 1998, the characteristics of the atmospheric duct were analyzed pre- and post- summer monsoon onset. The occurred probability of the atmospheric ducts became lower after the summer monsoon onset. The heights of the duct layers over the north SCS were elevated and those of the south SCS were reduced by summer monsoon prevailing. But duct-height amplitudes of variation in altitude were all within $300 \mathrm{~m}$. In addition, except that the duct strength of the north SCS changed a little during the active summer monsoon period, the other duct parameters of the SCS decreased especial duct characteristics of the south SCS such as about $40 \mathrm{~m}$ in thickness and $1 \mathrm{M}$ unit in strength. Those changes of the duct characteristics indicated the summer monsoon had important influence on the duct environment over the SCS.
\end{abstract}

Keywords-monsoon onset; atmospheric ducts; duct characteristics

\section{INTRODUCTION}

The atmospheric duct has been become an important field of propagation of radio waves with the technique of electromagnetic wave propagation wildly used recently, especially in the changeful troposphere. Because of radio wave anomalous propagation along the atmospheric ducts, the problems of the co-channel interference are more complicate for communication systems with the results of intersystem interference and the formation of other system. In addition, for surveillance equipments such as radar they can produce radar holes [1] or the extensions of detect range [2]. Biased on the observed data of the atmosphere or sea, the atmospheric ducts can be analyzed, estimated and forecasted, which has great theoretical significance and great value especially to military when the effects of the atmospheric ducts on propagation of radio waves and functions of surveillance equipments are estimated.

Because the diurnal marine atmospheric boundary layer changes slowly over the sea, the atmospheric ducts are stable and last for long. Many countries are interested in them. However, the sounding data over the sea are scarce and most

\author{
Zhou Sheng-qi \\ State Key Laboratory of Tropical Oceanography, LTO \\ South China Sea Institute of Oceanology, SCSIO \\ Guangzhou, China \\ e-mail: sqzhou@scsio.ac.cn
}

interior current studies were concentrated on the atmospheric ducts of the land or sea coast [3]-[6]. Only a few researches on the atmospheric ducts were involved in the South China Sea (SCS) [7]-[11].

The present analysis focused on the SCS atmospheric duct characteristics before and after summer monsoon onset based on the high-resolution GPS sounding data collected in the SCS Monsoon Experiment (SCSMEX) in 1998. The paper was organized as follows: section II describes the observation and data processing. The atmospheric duct characteristics of the SCS is described and discussed in section III and a summary is concluded in section IV.

\section{DATA AND METHOD}

\section{A. Data}

The SCSMEX was an international experiment designed to understand the key physical processes for the onset, maintenance and variability of the Southeast Asian monsoon. The field phase of SCSMEX was held from 1 May to 30 June 1998 during which two Intensive Observing Periods (IOPs) were conducted. During these IOPs, the extensive meteorological and oceanographic observations were taken over the SCS. An integral part of observational network during the IOPs included: two research vessels (R/V "Shiyan 3" located near (20N, 117E) and $\mathrm{R} / \mathrm{V}$ "Kexue 1" near $(6 \mathrm{~N}, 110 \mathrm{E})$ and related atmospheric sounding stations, such as Dongsha island and Nansha island sounding station, which took high resolution vertical soundings of the atmosphere. The profiling sounding dataset presented here includes the atmospheric pressure, temperature, dew-point temperature, altitude above mean sea level 4 profiles every day during the two IOPs. The observation stations used in paper are shown in Fig.1. 


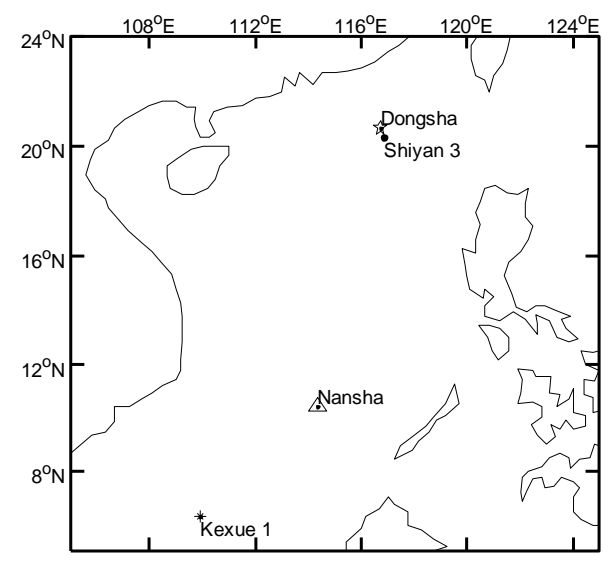

Figure 1. Map of the sounding stations during the two IOPs.

The data had been carried out quality control, higher time resolution and other improvements. After quality control, we got 547 times high-resolution sounding profiles. In order to analyze the duct characteristics of the north and south SCS, the dataset were grouped into two parts: the northern part and the southern part. The northern part included Dongsha Island and R/V"Shiyan 3" sounding stations and had 335 times vertical profiles. The southern part included Nansha Island and R/V "Kexue 1" sounding stations and had 212 times vertical profiles. On the basis of predecessors' work [12], the mean summer monsoon onset date of the north and south SCS was on 17th and 22th of May 1998 respectively. So the northern part included 131 times pre-onset of summer monsoon and 204 times during active summer monsoon. Similarly the southern part had 132 times pre-onset and 80 times post-onset of summer monsoon.

\section{B. Method}

Whether the atmospheric duct layer existing or not in the lower troposphere is determined by gradients of the radio refractivity of air. Under normal refractivity conditions, the radio refractivity near the surface of the earth decreases with elevation through the lower troposphere at a rate $40 \mathrm{~N} / \mathrm{km}$. When radio or radar signals travel in the abnormal refractivity conditions in which the curvatures of their paths are greater than the earth's surface curvature, the atmospheric duct layer forms. For microwaves in the frequency range from $300 \mathrm{M}$ to $300 \mathrm{GHz}$, the modified refractivity $M$, which takes the earth's curvature into account, is written in terms of atmospheric pressure, air temperature, water vapor pressure and altitude. The expressions are given by Liu at el [6]:

$$
M=\frac{77.6}{T}\left(P+4810 \frac{e}{T}\right)+0.157 z
$$

Where $\mathrm{P}(\mathrm{hPa})$ is the atmospheric pressure, $\mathrm{T}(\mathrm{K})$ is the air temperature, $\mathrm{e}(\mathrm{hPa})$ is the water vapor pressure, $\mathrm{z}(\mathrm{m})$ is altitude. When the atmospheric duct layer forms, the gradients of the modified refractivity are limited:

$$
\frac{d M}{d z}<0
$$

The strength of ducts is given by equation (3) [11]:

$$
\lambda_{\max }=\frac{2}{3} C d \delta M^{1 / 2}
$$

Where ${ }_{\max }(m)$ is the maximum wavelength trapped by the duct. $\mathrm{C}=3.77 \times 10-3$ for a surface-based duct, $\mathrm{C}=5.66 \times 10-3$ for an elevated duct, $\mathrm{d}$ is the depth of the duct and $\delta M(m)$ is the duct thickness. Large value of $\lambda_{\max }$ indicates a strong duct which traps the microwaves much easier. Using the formula (2) and the $\lambda_{\max } \geq 1$, the collected data profiles were analyzed. The water vapor pressure is calculated using (4)[13].

$$
e=6.11 \times \exp \left(19.7 \times \frac{T_{d}\left({ }^{\circ} C\right)}{T_{d}\left({ }^{\circ} K\right)}\right)
$$

Where e (hPa) is the water vapor pressure, $T_{d}$ is the dewpoint temperature. In order to eliminate the negative effects caused by the atmospheric turbulence and noise of instruments, the vertical modified refractivity profiles were smoothed with irregularly spaced five-point and cubic polynomial.

\section{RESULTS}

\section{A. Occurred probobility of the ducts}

The factors that cause the atmospheric duct layer are complicated and atmospheric refractivity profiles are often changeable or have multilayer duct layers. So the study of this paper focused on the lower and strong atmospheric duct layer below $3 \mathrm{~km}$ vertical height. The strong duct layers can better show the typical atmospheric structure and related stability.

There were 211 times profiles where the atmospheric ducts occurred. So the occurred probability of the atmospheric ducts over the SCS was about 38\%. Among the occurred atmospheric ducts, the ratios of the elevated duct, the complex duct, the others accounted for $72 \%, 26 \%$ and $2 \%$, respectively. From the whole statistical analysis, the majority of the ducts were of the elevated type over the SCS. So we investigated the first duct layer in this paper. The occurring conditions of the two parts

\begin{tabular}{|c|c|c|c|c|c|}
\hline \multicolumn{2}{|c|}{ groups } & \multirow{2}{*}{$\begin{array}{c}\begin{array}{c}\text { Total } \\
\text { times/ } \\
\text { Occurred } \\
\text { times }\end{array} \\
131 / 53\end{array}$} & \multirow{2}{*}{$\begin{array}{c}\begin{array}{c}\text { Occurred } \\
\text { Probability } \\
/ \%\end{array} \\
40\end{array}$} & \multirow{2}{*}{$\begin{array}{c}\begin{array}{c}\text { Ratio of } \\
\text { the } \\
\text { elevated } \\
\text { duct } / \%\end{array} \\
73\end{array}$} & \multirow{2}{*}{$\begin{array}{c}\begin{array}{c}\text { Ratio of } \\
\text { the } \\
\text { complex } \\
\text { duct } / \%\end{array} \\
23\end{array}$} \\
\hline & Before & & & & \\
\hline North & After & $204 / 57$ & 28 & 72 & 24 \\
\hline \multirow{2}{*}{ South } & Before & $132 / 66$ & 50 & 61 & 39 \\
\hline & After & $80 / 33$ & 41 & 88 & 10 \\
\hline
\end{tabular}
before and after summer monsoon onset were listed in Tab.1.

TABLE I. OCCURRED PROBOBILITY OF THE ATMOSPHERIC DUCTS BEFORE AND AFTER SCS SUMMER MONSOON ONSET

Tab.1 shows that the occurred probability of the atmospheric ducts over the SCS is different before and after the summer monsoon onset. As a whole, the occurred probability during the 
pre-onset summer monsoon period decreases than the active summer monsoon. The occurred probability over the north and south SCS before summer monsoon are about $40 \%$ and $50 \%$ respectively. After the summer monsoon onset they reach only about $28 \%$ and $41 \%$ respectively. The changeable amplitudes of the occurred probability over the north and south SCS are about $12 \%$ and $10 \%$ respectively.

A noteworthy fact is the ratio of the duct type. The ratios of the elevated duct and complex duct to the occurred ducts over the north SCS are little change and they account for about $73 \%$ and $23 \%$ respectively. However, the ratio of each duct type to the occurred ducts over the south changes sharply. The ratio of the elevated duct over the south SCS can be improved from about $61 \%$ before the summer monsoon onset to $88 \%$ after the summer monsoon onset. While the ratio of complex duct before and after summer monsoon onset changes opposite to that of the elevated duct over the south SCS.

And here it becomes evident, that the summer monsoon onset had an important effect on the formation of the atmospheric ducts over the SCS and seemed not to be conducive to ducts environment occurring. As a matter of fact, after the summer monsoon onset the wind over the SCS changed from south-east to south-west and the wind speed became larger. The south-west monsoon, that is summer monsoon, brought much warm vapor and mixed water vapor and heat well in the atmospheric boundary layer so that the atmospheric ducts occurred less.

\section{B. Other characteristics of the ducts}

For precise descriptions of the atmospheric duct, the ductbottom height, thickness and strength were carried out statistical investigation and the mean numbers were listed in Tab. II.

TABLE II. MEAN PARAMETERS OF THE DUCTS BEFORE AND AFTER SUMMER MONSOON ONSET

\begin{tabular}{|c|c|c|c|c|}
\hline \multicolumn{2}{|c|}{ Stations } & $\begin{array}{l}\text { Mean duct- } \\
\text { bottom height /m }\end{array}$ & $\begin{array}{l}\text { Mean duct- } \\
\text { thickness /m }\end{array}$ & $\begin{array}{c}\text { Mean duct- } \\
\text { strength /M } \\
\text { unit }\end{array}$ \\
\hline \multirow{2}{*}{ North } & Before & 502 & 188 & 8.9 \\
\hline & After & 727 & 183 & 9.2 \\
\hline \multirow{2}{*}{ South } & Before & 795 & 208 & 10.1 \\
\hline & After & 519 & 182 & 8.8 \\
\hline
\end{tabular}

spheric duct parameters over the north SCS except the ductbottom height are almost constant. The duct thickness and strength over the north SCS remain at around $185 \mathrm{~m}$ and $9 \mathrm{M}$ unit respectively although the summer monsoon was prevailing over SCS. However the duct-bottom height over the north SCS becomes higher from $500 \mathrm{~m}$ to $730 \mathrm{~m}$. For the south SCS, all the duct characteristics decrease after the monsoon onset and the duct-bottom height change from $800 \mathrm{~m}$ around to about $500 \mathrm{~m}$. Other duct parameters are similar to the duct-bottom height, the duct thickness changing from about $210 \mathrm{~m}$ to $180 \mathrm{~m}$ and the duct strength also becoming weak from $10 \mathrm{M}$ unit to $9 \mathrm{M}$ unit after the summer monsoon onset.

Those changes of the duct characteristics indicated the summer monsoon had important influence on the duct environment over the SCS again. The summer monsoon onset elevated the heights of the lower atmospheric duct layers over the north SCS and reduced the heights of the lower atmospheric duct layers over the south SCS, whose amplitudes of variation in altitude were all within $300 \mathrm{~m}$. In addition, except that the duct strength of the north SCS became a bit stronger during the active summer monsoon period, but others of the SCS decreased especial those of the south SCS such as about $40 \mathrm{~m}$ in thickness and $1 \mathrm{M}$ unit in strength. In addition, the differences of the atmospheric ducts gave a signal that the mainland had some effect on the duct environment over the SCS, which needs to do further research.

\section{CONCLUSIONS}

Lower atmospheric ducts over the sea occur mainly in the marine atmospheric boundary layer. The synoptic situation and process during the monsoon period mainly affect atmospheric ducts' building. The datasets collected during 1998 monsoon period over the SCS were analyzed and primary characteristics were concluded.

The occurred probability of the atmospheric ducts became lower after the summer monsoon onset. The heights of the duct layers over the north SCS were elevated and those of the south SCS were reduced by summer monsoon prevailing. But ductheight amplitudes of variation in altitude were all within $300 \mathrm{~m}$. In addition, except that the duct strength of the north SCS changed a little during the active summer monsoon period, the other duct parameters of the SCS decreased especial those of the south SCS such as about $40 \mathrm{~m}$ in thickness and $1 \mathrm{M}$ unit in strength. Those changes of the duct characteristics indicated the summer monsoon had important influence on the duct environment over the SCS.

\section{ACKNOWLEDGMENT}

The work was supported by National Foundation of China (Grant NO. 41106011 and 41176027), Open Fund of the Key Laboratory of Ocean Circulation and Waves, Chinese Academy of Sciences (NO. KLOCAW1103).

\section{REFERENCES}

[1] J. E. Freehafer, D. E. Kerr. Tropospheric refraction propagation of Short Radio Wave. Gallipoli: Peninsula Publishing, 1988, pp.9-22.

[2] L.J.Battan, Radar observation of the atmosphere. Chicago: University of Chicago Press, 1973, pp.324.

[3] L. Jiao, Y. Zhang, Study of the shadowzone of the radar in the atmospheric duct. Journal of Xidian University, vol.31(5), 2004, pp.815-820.(in Chinese)

[4] C. Liu, Z. Pan, L. GUO. Statisticalanalysis of occurrence and characteristics of atmospheric ducts in China, Chinese Journal of Radio Science, vol.11(2), 1996 , pp.60-66.(in Chinese)

[5] F. Lin, C. Liu, S. Cheng,et al, Statistical analysis of marine atmospheric duct. Chinese Journal of Radio Science, vol.20(1), 2005, pp.64-68. (in Chinese)

[6] C. Liu, J. Huang, C. Jiang.The occurrence of tropospheric ducts over the south-eastern coast of China. Chinese Journal of Radio Science,vol.17 (5) ,2002, pp.509-513. (in Chinese) 
[7] V. E. Axel, G. Nedoluha, T. Joao, An analysis of the frequency and distribution of ducting events in simulated radio occultation measurements based on ECMWF fields, J.Geophys.Res, vol. 108(D21), $2003 \quad$,pp. ACL3-1-ACL3-12, doi:10.1029/2002JD003170

[8] V. E. Axel, T. Joao. A ducting climatology derived from ECMWF global analysis fields,J.Geophys.Res, vol.109(D18), 2004, pp. 1-18, doi:10.1029/2003JD004380.

[9] L. Sun. Analysis and preliminary research with numerical simulation of the atmospheric duct in the South China Sea, Lanzhou Gansu: Lanzhou University, 2009.(in Chinese)

[10] L. Chen, S. Gao, S. Kang,et al. Statistical analysis on spatialtemporal features of atmospheric ducts over Chinese regional seas,
Chinese Journal of Radio Science, vol. 24(4), 2009, pp.702-708. (in Chinese)

[11] Y. Cheng, A study on atmospheric ducts over the sea retrieval with AMSR-E satellite data and its numerical simulation, Beijing: Graduate School of Chinese Academy of Sciences, 2009.(in Chinese)

[12] Y. Ding, C. Li, J. He, et al, South China Sea monsoon experiment(SCSMEX) and the east- Asian monsoon, Acta Meteorologica Sinica, vol. 2(62), 2004, pp.561-586.(in Chinese)

[13] S. Cai.The research of evaporation duct in Taiwan,Taiwan China: National Central University, 2005.(in Chinese) 